\title{
Family Networks' Support to Employment Paths of Rural Youth in a Ghanaian Community
}

\author{
Peter Dwumah $^{1}$, Kofi Osei Akuoko ${ }^{1}$, \& Eric Henry Yeboah ${ }^{1}$ \\ ${ }^{1}$ Department of Sociology and Social Work, Kwame Nkrumah University of Science and Technology, Kumasi, Ghana \\ Correspondence: Peter Dwumah, Department of Sociology and Social Work, Kwame Nkrumah Uni versity of Science and \\ Technology, Kumasi, Ghana.
}

Received: August 4, 2017

doi:10.11114/ijsss.v6i2.2577
Accepted: November 11, $2017 \quad$ Available online: January 5,2018

URL: https://doi.org/10.11114/ijsss.v6i2.2577

\begin{abstract}
The study examined family networks' support to rural young people's past and present employment as well as their employment aspirations since research on these issues especially in African and Ghanaian context is rare. The research analysed whether or not rural youth expect and receive employment support from their family networks. Mixed method approach for collection and analysis of data from young people in Amankyea a rural community in the Atwima Nwabiagya district of Ashanti region in Ghana was used. Three (3) focus group discussions and interviews of 20 young people who were purposively selected were conducted. Questionnaires were also administered to 270 randomly selected young people in the rural community. Social capital theory was used as theoretical framework for the study. It was found that majority of the rural youth did not expect, and receive employment support from their family networks. Though rural youth did not expect support from their family networks generally, female rural youth expected and received support from their male partners. The study recommends the need to encourage family networks through workshops and seminars to prioritize employment support to rural young people to reduce reliance on government of Ghana.
\end{abstract}

Keywords: social networks, social capital, youth, employment, career, Ghana

\section{Introduction}

Family relations constitute an important aspect of social network analysis. Family life is regarded as the "bedrock of social capital" (Winter 2000, p.5) and is the main place for accumulation and transmission of social capital (Bourdieu, 1993). Although not all families are able to provide the same degree and kind of support and therefore vary in the degree of social capital they provide (Barker, 2012), family networks have the potential to provide employment support to rural young people in Ghana and other countries as a result of the absence of public support systems. This view of family networks support is emphasized by the tradition and culture of the Ghanaian society. The social capital theory also advances this position. The theory argues that there are benefits obtained from the social relations of people (Bourdieu, 1985; Gargiulo \& Benassi, 2000; Acquaah, 2006; Barker, 2012).

Despite the immense potential of family and other social networks' support to rural youth employment, research into the issue is not well documented. Some empirical studies have been conducted to identify the influence of parents (Mau \& Bikos, 2000; Kniveton, 2004; Mudhovozi \& Chireshe, 2012; Shumba \& Naong, 2012; Wu, 2012) on the employment choices and aspirations of people. These studies focused mainly on young people who are students and not those who are out of school in rural areas. These studies did not explore the influence of other members within the extended family system such as uncles, aunts, grandparents and cousins among others, who may be important when examining the employment paths of rural young people in an African context such as Ghana. This study therefore sought to examine whether the youth in a rural Ghanaian community (Amankyea), expect and receive employment support from their family networks.

\section{Literature Review}

This section presents the theoretical framework and review of the literature on the concept "family" and its influence on the employment trajectories of the youth especially those in rural communities. 


\subsection{Theoretical Framework: Social Capital Theory}

Social capital is a concept that comes up in the analysis of social embeddedness and social networks. Pierre Bourdieu and James Coleman contributed to the initial development of the concept of social capital by highlighting the benefits accruing to individuals or families from their social ties (Byun, Meece, Irvin and Hutchins, 2012). Bourdieu (1985) defines social capital as "the aggregate of the actual or potential resources which are linked to possession of a durable network of more or less institutionalised relationships of mutual acquaintance and recognition, in other words, to membership in a group." Bourdieu's examination of social capital points out the benefits obtained from involvement in groups as well as social ties (Barker, 2012). Culminating from the social networks, social actors can gain economic capital such as loans, employment and cultural capital such as information, education and social status (Barker, 2012). It is worthy to note however that not all social relations develop into social capital. Benefits may not accrue from some social relations (Barker, 2012). The study recognises that the youth can obtain employment support from family members as social actors.

\subsection{Conceptualization of Family}

To be able to undertake a thorough discussion on the influence of family on rural young people's employment, the notion of family ought to be touched upon as the set-up and its conception differ in various societies. Western conception of family for instance differs from how family is perceived in Africa (Mbiti, 1969). In sociological studies therefore the definition of family is not universally agreed upon (Giddens \& Sutton, 2013). The complexity in defining the concept "family" as Giddens \& Sutton (2013) note results from the different family forms available which includes heterosexual families, same-sex families, step-families and single-parent families. A definition of family that is often stated is a group of persons directly linked by kin connections, the adult members of whom assume responsibility for caring for children (Giddens \& Sutton, 2013). Giddens \& Sutton (2013) further write that sociologists and anthropologists distinguish between nuclear and extended families. Nuclear family involves two adults who live together in a household with their own or adopted children while with the extended family there is the inclusion of close relatives living in the same household with the members of the nuclear family or in a close and continuous relationship with them (Giddens \& Sutton, 2013). So whilst the western notion of nuclear family consisting of parents and children is widely asserted, "for African people the family has a much wider circle of members. In traditional society, the family includes children, parents, grandparents, uncles, aunts, brothers and sisters who may have their own children and other immediate relatives" (Mbiti, 1969, p.106). The relationships within extended family would be based on kinship (biological or putative blood relationship) and affinity (relationship between blood relationships of one marriage partner and those of the other marriage partner). Such a family would include adopted and fostered children. The extended family may include grandparents, brothers and their wives, sisters and their husbands, aunts and nephe ws (Giddens \& Sutton, 2013).

This study examines both nuclear and extended family. Family members in this study therefore include father, mother, siblings, partner, grandparent, uncle, aunt and cousin.

\subsection{Employment Situation in Ghana}

In Ghana, out of the total population of 21,253,417 aged 5 years and older, $54.2 \%$ is economically active (employed and unemployed) while the economically not active population (not employed, not seeking nor available for work) constitutes 45.8\% (GSS, 2012). Agriculture, including forestry and fishing, remains the largest industrial sector employing $41.5 \%$ of the economically active population aged 15 years and older. The next major industrial activities are wholesale and retail trade (18.9\%) and manufacturing $(10.8 \%)$ (GSS,2012). Data on employment status indicates that majority $(64.8 \%)$ of the economically active population are self-employed. Employees constitute $18.2 \%$ while contributing family workers make up $11.5 \%$. Apprentices form only $2.7 \%$ of the economically active population. Private sector is the largest employer in the country, accounting for $93.1 \%$ of the economically active persons (private informal, $86.1 \%$ and private formal, $7.0 \%$ ). The public sector, which is the second largest employer, accounts for only $6.3 \%$ (GSS, 2012)

The employment problem in Ghana directly links to the increasing levels of poverty. The most fundamental cause of poverty in Ghana is the absence of productive jobs, which leads to low rates of employment and income. Attempts to tackle poverty therefore require the creation of productive and quality employment opportunities (Ministry of Employment and Labour Relations, 2014).

Youth employment remains a challenge in Ghana with its youthful population structure. Arguably the World Development Database in 2012 puts Ghana's youth unemployment rate at 15.9\% (Baffour-Awuah, 2013). As Amankrah (2012) writes, the continuous growth in the labour force, unaccompanied by corresponding expansion in the productive economy have created unemployment and vulnerable employment challenges especially among the youth, culminating in growing youth unemployment. The increasing incidence of street hawking and migration of Ghanaian youth across 
the Sahara Desert and the Mediterranean in search of economic opportunities in Europe, with its attendant risk, are not only symptoms of labour market challenges facing the youth but also a reflection of a sense of hopelessness (Baffour-Awuah, 2013).

The incidence of youth unemployment has led governments in Ghana in recent times to develop various youth employment policies including National Youth Employment Programme (NYEP), Ghana Youth Employment and Entrepreneurial Development Agency (GYEEDA) and Youth Enterprise Support (YES) programme. Ultimately, the Government of Ghana's 2014 National Employment Policy (NEP) is 'to leverage Ghana's natural resource endowments, agriculture potentials and human resource base for accelerated economic growth and job creation through value addition, especially manufacturing" (Ministry of Employment \& Labour Relations, 2014: 14).

\subsection{Influence of Family on Youth Employment}

The family both nuclear and extended in Ghana have some significant influence on youth employment especially in the rural areas (Aryeetey et al, 2013; Okali \& Sumberg, 2012). Members of the extended family such as stepparents, grandparents, foster parents, uncles, aunts, and others who played active roles in the youth's development can be as influential as their parents on their career choices and aspirations depending on the level of interaction and relational proximity (Whiston \& Keller, 2004). Salami (2006) therefore finds that in career choice the most significant predictor is family involvement. As indicated by Shumba \& Naong (2012), in explaining career choices of students in South Afric a, the family is the most important factor, followed by the individual's ability to identify the preferred choice, and the teachers. Information and guidance are provided by the family, during career choice of youth whether directly or indirectly (Kniveton, 2004). The root of the huge familial influence on career decisions as observed by Whiston \& Keller, (2004, p. 494) is that "for many individuals, relationships with family members are some of the most potent and significant relational experiences in their lives". Salami (2006) writes that the extent to which parents or family members participate in the career planning of children, provide encouragement, approval and financial support can be regarded as family involvement. In gender dominated occupations the most significant predictor of career choice was found to be family involvement (Salami, 2006). Whiston \& Keller (2004) assert that children who perceive their families as supportive and as having high expectations tend to have higher occupational aspirations than others. Rush (2002) also notes that having a supportive family environment is associated with successful negotiation of career development (Rush, 2002 cited in Wong \& Liu, 2009). Ferry (2006) found that 'the lack of family involvement in the career choice process appeared to be influencing youth inability to make [career] decisions.

However, while family influence on youth career decisions are largely positive, this is not always the case. Blustein (2004) notes that "family relationships are a complex mosaic of emotional tugs, psychologically subtle balances, and elusive family mores that are difficult to isolate and fully comprehend" (Blustein, 2004: 605 cited in Whiston \& Keller, 2004, p. 612). Whiston \& Keller (2004) also caution that family influences on career development are multifaceted and should therefore not be simplistically viewed in terms of cause and effect. In child and parent interaction, the penchant to influence the child to pursue career that the family thinks is desirable is always real. In cases where such parental preference is at variance with the child's interest, tension emerges. Children who will for fear of offending their family succumb to the family choices may pursue the careers foisted on them and may fail eventually or experience job dissatisfaction in later years whilst others may rebel. As noted in Alika (2012, p. 538) such "career choice may lead to unhappiness, disapproval by the society, and difficulty in coping with life tasks". Whilst conceding that some reviewe d studies indicate that "family support may facilitate career development, Whiston \& Keller (2004, p. 613) argue as well that such "findings are vague and difficult to interpret in a theoretical vacuum". Whiston \& Keller (2004) reported that family of origin undermined the career development of some students. Although the negative influence of family on youth career choices ought not to be lightly treated, usually the studies that report on this also make positive findings as well (Whiston \& Keller, 2004). This may mean that the nature of the influence - whether negative or positive may not be determined by family per se as an institution. What therefore may be important is what goes on in the family. This makes Alderfer's admonition worth heeding to. Alderfer (2004, p. 570) suggests that in examining the influence of the family on youth career choices and aspirations, what is "important [is] to determine what kind of family structure and process would facilitate positive parental involvement."

Membership of the family per se however may not matter much in youth employment but will largely depend on the frequency of interaction and how close the family member is to the individual. Generally, parents are closer to and frequently interact with their children than any other member(s) of the (extended) family (Wong \& Liu, 2009). Wong \& Liu $(2009$, p. 83) argue that the family and most especially "parents play a very important role in all aspects of a young person's life, including those critical decision-making points such as choosing a career". Parental influences, which comprise the main family influence, are both distal and proximal contextual cognitive factors, and exert a salient effect on their offspring's career choice intention. As noted by Lent and Brown, parental influences are powerful contextual determinants that mediate the relationship between interests and goals, between goals and actions, and between actions 
and accomplishments (Lent \& Brown, 1996 cited in Wong \& Liu, 2009). Vocational interests, Whiston \& Keller (2004, p. 519) contend, "develop, in part, as a result of interactions and identifications with significant others". Most people claim that their career choices are made collaboratively with their parents and some even consider "their parents [as] the main drivers behind their actual decisions" (Wong \& Liu, 2009, p. 85).

Kellaghan et al. (1993) summarize and divide parental influences through two macro perspectives: the "who parents are" perspective and the "what parents do" perspective (cited in Wong \& Liu, 2009, p. 85). Thus, the socio-economic status of parents has some influence on the career choices their children make. As a distal contextual career-influencing factor, the parents' socio-economic status sets a stage for experience that influences many dimensions of their children's lives (Liu, 2002; Liu et al., 2004; Maher \& Kroska, 2002 cited in Wong \& Liu, 2009), including the educational and occupational opportunities available to that individual and the attainments that he or she achieves (Brown, 2002; Fouad \& Brown, 2000; Gilbert \& Kahl, 1993; Turner \& Lapan, 2003 cited in Wong \& Liu, 2009). Parents' socio-economic status variables usually interact with their proximal variables to influence the development of their children's career interests, the exploration and selection of their career goals, and their career behaviours (Ali et al., 2005 cited in Wong \& Liu, 2009; Ferry, 2006). Parental education variables, as Eccles (1993) suggests, have an impact on the beliefs and behaviours of the parents, indirectly leading to positive career outcomes for the young people concerned (Eccles, 1993 cited in Wong \& Liu, 2009). A review of the empirical literature indicates that the socio-economic status of the family of origin has consistently been shown to demonstrate a significant effect on a number of career development variables (Brown, Fukunaga, Umemoto, \& Wicker, 1996 cited in Whiston \& Keller, 2004).

But interestingly, Trusty et al (1997) found that family's socio-economic status "accounted for less than $1 \%$ variance in predicting the degree to which parents were involved in their children's career development". The study also found no support for the "speculation that parents of lower socioeconomic status spend less time than middle-class parents in career development activities" (Trusty et al, 1997 cited in Whiston \& Keller, 2004, p. 525). Ngesi (2003) finds that students with low economic background are less likely to choose careers requiring long training period and financial support. Similarly, Bojuwoye \& Mbanjwa (2006) identify lack of finance as a factor that impact on tertiary students' career choices. Reviewing the literature on socio-economic status and aspirations, Howard et al (2011) conclude that family socio-economic position has between small but significant to a large effect on career aspirations of the youth. Salami (2006) also notes that the higher the socio-economic status of parents the greater the opportunities available in terms of financial resources, material resources and information about occupations. Other studies have found that career aspirations are greatly influenced by parents' aspirations or expectations. Wu (2012) studying Taiwanese Aboriginal students found that students' career aspirations were most importantly influenced by parents' occupational aspirations for the children. Shumba \& Naong (2012) also write that according to most studies parents' aspirations influence adolescents' aspirations.

Studies have also examined each parent's influence on employment and career choices of children. Mothers have been identified as playing a more influential role in career decision. Muthukrishna \& Sokoya (2008) finds that in career choice mothers are the most influential people adolescents communicate with. In a similar vein, Bojuwoye \& Mbanjwa (2006) in their research on South African students' reports that mothers were more influential in their career choices. Children's concerns about careers and employment are eased by the support of mothers (Shumba \& Naong, 2012).

To further understand the role of parents in the lives and careers of young people, cultural differences should be considered (Taylor et al., 2004 cited in Wong \& Liu, 2009, p. 86). Individualistic cultures emphasize autonomy and individuation from parents (Hardin et al., 2001 cited in Wong \& Liu, 2009). Thus parents in an individualistic cultural setting are likely to have relatively little impact on an individual's career choice. For example, American culture views career choice as a means of self-actualization, and fundamentally as an individual choice (Tang et al., 1999 cited in Wong \& Liu, 2009). However, in the context of a collectivistic culture, the salience of parental influences on a young person's career choice is frequently examined in the light of the importance of interdependence, respect paid to authority and older people, family accord, and conformity with social norms (Moy, 1992 cited in Wong \& Liu, 2009). Similarly, Lee (1991) suggests that collectivistic cultural values often manifest in a strong re spect for and obedience to one's parents and to the traditions of the family or group (cited in Wong \& Liu, 2009). Accordingly, in places like Africa where high cultural value is placed on parents, the family and communal living, the family will be central to youth career choices and aspirations than in the West where the phenomenon of legal subject, the largely autonomous individual conceived as a bundle of rights is widely asserted. The socio-cultural system of Ghana is highly collectivistic and embedded in cultures and traditions that thrive on communal bonds, interpersonal relationships and strong allegiance to community and family leadership (Adu-Febiri, 1995 cited in Acquaah, 2011). The extended family and broader community (especially kings of ethnic groups, chiefs of towns and cities and village heads) are seen as the cultural standard bearers, and they play a critical function in the lives and activities of individuals and organizations.

In Ghana few studies have been conducted to examine the relations between family networks and young people's 
behaviour especially employment decisions. Yeboah (2010) writing on microfinance intervention for rural women in Ghana referred to family, kindred organization and friends as social networks, who provide financial support and social welfare to people. In Ghana remittances from extended family members abroad form an important source of financial assistance (Yeboah, 2010). However, he notes that the influence of social networks as a financial resource is usually understated, especially in rural areas of Ghana. Traditionally, the extended family is the first place to go, when a member requires financial resources for any venture or in an emergency situation (Yeboah, 2010). Members of the extended family are required to offer financial assistance during times of emergencies and crises such bereavement, illness, drought, and floods (Yeboah, 2010). Langevang (2008) also states that traditionally in Ghana social networks based on family constitute an important resource in the training and upbringing of young ones. She reports the reciprocal role evident in the relations between the young and parents or older family members. The young ones consider their parents or older members of the family as responsible for helping them find their feet in life. Their role in return is to respect them, help in daily activities, the upbringing of younger ones and ultimately support the elderly.

In their analysis of the choice of skills training of Ghanaian youth, Aryeetey et al (2013) find that extended family were highly influential. They note from a focus group discussion that uncles and aunts were identified as most influential. This finding is consistent with the views of Assimeng (2006) that even though humans are genetically constituted, who they become is influenced by their continuous interaction with the social context. It is considered the responsibility of extended family members to be involved in the decisions of others (Aryeetey et al, 2013). This portrays the idea of collective responsibility that characterizes family institution in Ghanaian societies. Okali \& Sumberg (2012) analyze how family networks help people to acquire land for tomatoes farming in Pamdu, a village in Brong Ahafo region of Ghana. They find that $40.5 \%$ of individuals get access to land through the family of their father or mother.

This study therefore was conducted to add to the limited literature on family networks and rural youth employment in Ghana. The family examined in this study goes beyond the nuclear family to include the extended form as noted by Giddens \& Sutton (2013).

\section{Methods}

This section presents the research design, unit of analysis, population, target population, sampling, methods of data collection and analysis as well as ethical considerations.

\subsection{Research Design}

This study adopted a case study design utilizing mixed methods for collection and analysis of data from rural youth in Amankyea, a rural Ghanaian community. Mixed method was useful since it allows researchers to collect richer data and examine more complicated questions that a single (quantitative or qualitative) approach may not be able to address alone (Yin, 2009). The qualitative data provided explanation of concepts and gave an in-depth explanation of how the employment paths of young people in the rural area were supported by their family networks. On the basis of the focus group discussions and interviews, questionnaire was constructed to examine views of rural youth in terms of family networks' support to their employment paths.

\subsection{Unit of Analysis}

The views of rural youth who were between 18 and 40 years constituted the unit of analysis. This age group was based on the young people's definition of the youth during the focus group discussions.

\subsection{Study Population}

The study population were youth between 18 and 40 years who were out of school irrespective of the sex and type of employment. This age categorization was developed by the young people during focus group discussions. The criteria developed by young people in the conceptualization of "youth", was used for estimating the study population for the survey.

Developing the sampling frame the researcher identified the number of households in the community with out-of-school young people between the ages of 18 and 40 years. This was done because of the absence of a sampling frame. The number of households identified was 272. Each household had an average of 3 out-of-school youth. The study population was therefore estimated as 816 out of which 270 were selected

\subsection{Sample Selection}

In determining the sample size for the quantitative data collection, the study used 270 respondents to enhance the statistical generality of the findings within the context.

Israel (2009) proposes the formula below, which was adopted by the researcher in the selection of the sample size: 


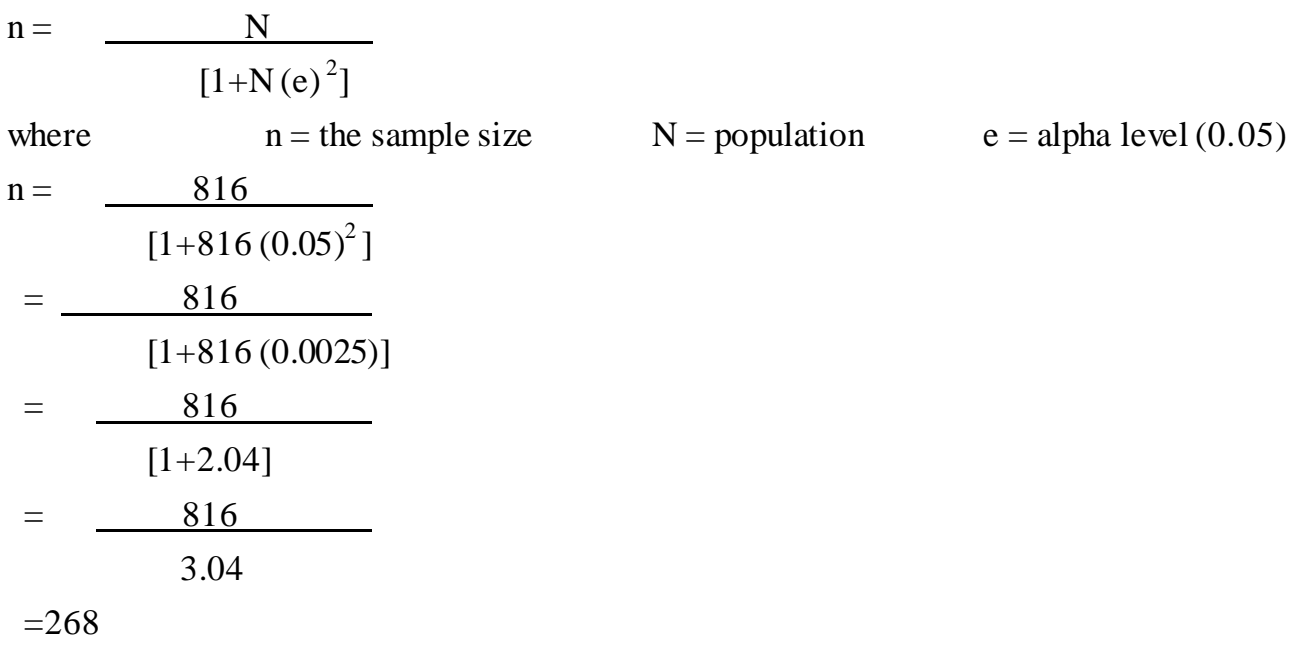

The sample size of 270 respondents completed the questionnaire for the quantitative data collection. The researchers selected one youth from each household for the inclusion of all the qualified households in the community. By this approach the views of members of all qualified households were captured, enhancing the validity of the findings.

To obtain the qualitative information, the maximum variation sampling technique was utilised. As Patton (2002, p. 234) notes, with maximum variation sampling, "common patterns that emerge from great variation are of particular interest and value in capturing the core experiences and central, shared dimensions of a setting or phenomenon". By using maximum variation the researcher intentionally included youth from both genders as well as from the different employment options they engaged in. As such males, females, youth in agricultural employment, youth in non-agricultural employment and the youth in both agricultural and non-agricultural employment were included in the study. This maximum variation sampling helped to capture diversity of views.

The researcher therefore selected 20 respondents for the individual interviews, made up of 10 males and 10 females. Three (3) focus group discussions was organised, constituting a group made up of males only, another group made up of females only and one that combined both males and females. These groups had 7 members each and provided diversity of opinions from the different genders. The individual interviews and focus group discussions provided the qualitative data for the study.

\subsection{Data Collection Methods}

Data for the study was obtained from both primary and secondary sources. Data was collected during eight (8) months period from December, 2013 to July, 2014. Inspired by Langevang (2007), a multi-method strategy was used in the qualitative data collection including interviews and focus group discussions. Interview guides were used to ensure the discussions between researcher and participants were somehow structured.

Questionnaire was used to gather quantitative data. Since the questionnaire was to be translated into the local language (Twi) from the English language, the researcher ensured that the questions were simple and unambiguous to avoid misinterpretation. The use of the local language was appropriate since majority of respondents were not literate enough to answer the questions on their own. The questionnaire was therefore researcher administered.

\subsection{Ethical Considerations}

The study acknowledged relevant ethical issues to ensure the credibility of the research. To satisfy ethical considerations in relation to intellectual or academic property and honesty, all secondary data used in the study were duly acknowledged. Indi vidual informed consent was obtained from all participants. The nature and the purpose of the study were explained to the participants. Participants who could read and write self- completed the informed consent form and signed while the researcher completed the form on behalf of those who could not read and write. Such people thumb printed the completed form. In order to ensure privacy of the participants of the study, participants were not made to provide any form of personal identification. With reference to the interviews, pseudonyms were used instead of the real names of participants to ensure anonymity. Also the confidentiality of the participants was ensured by not sharing or releasing information to others who were not directly involved in the study.

\subsection{Data Analysis}

The study adopted the inductive and deductive approaches in the analysis of the qualitative data. Using the inductive approach, the researcher prepared and organized the qualitative data, reduced them into themes by coding and condensing the codes. The researcher also adopted the deductive approach by making reference to concepts derived from the literature review. 
The quantitative data collected through the survey instrument was coded, edited, entered into the Statistical Package for Social Sciences (SPSS) software version 20 and cleaned. The descriptive results were then presented in the form of frequency tables and line charts. The study analysed the socio-demographic characteristics of respondents including their age, sex, educational level, marital status and religion. It also examined whether or not rural youth expected employment support from the family, both nuclear and extended. Again data was analysed in relation to whether or not the rural youth received support from their family members. Analysis of expectation and actual receipt of support was done in relation to the rural youth's past, present and future employment. Past employment was conceptualised as the immediate economic activity the rural youth engaged in before their current economic activity. Present employed was defined as the economic activity the rural youth currently engaged in. Future employment referred to the economic activity the rural youth aspires to be involved in.

\section{Results and Discussion}

This section presents the results and discussion of data collected on family networks' support to rural youth employment. It has been categorised into socio-demographic characteristics of respondents, expectation and receipt of employment support from nuclear and extended family members.

\subsection{Socio-demographic Characteristics of Respondents}

The study examined the socio-demographic characteristics of respondents. It analysed the age, sex, educational level, marital status and religion of respondents as presented in Table 1 below.

Table 1. Socio-demographic characteristics

\begin{tabular}{|c|c|c|}
\hline $\begin{array}{l}\text { Socio-demographic } \\
\text { characteristics }\end{array}$ & Frequency & Percent \\
\hline \multicolumn{3}{|l|}{ Age } \\
\hline$\overline{18-25}$ & 94 & 34.8 \\
\hline 26-30 & 92 & 34.1 \\
\hline 31-35 & 55 & 20.4 \\
\hline $36-40$ & 29 & 10.7 \\
\hline Total & 270 & 100 \\
\hline \multicolumn{3}{|l|}{$\underline{\operatorname{Sex}}$} \\
\hline$\overline{\text { Male }}$ & 116 & 43.0 \\
\hline Female & 154 & $\mathbf{5 7 . 0}$ \\
\hline Total & 270 & 100 \\
\hline \multicolumn{3}{|l|}{ Education } \\
\hline No schooling & 22 & 8.1 \\
\hline Primary Education & 88 & 32.6 \\
\hline Junior High Education & 122 & 45.2 \\
\hline Senior High Education & 20 & 7.4 \\
\hline Technical/Vocational Education & 18 & 6.7 \\
\hline Total & 270 & 100 \\
\hline \multicolumn{3}{|l|}{ Marital status } \\
\hline$\overline{\text { Married }}$ & 91 & 33.7 \\
\hline Co-habitation & 83 & 30.7 \\
\hline Never married & 65 & 24.1 \\
\hline Separated/Divorced & 26 & 9.6 \\
\hline Widowed & 5 & 1.9 \\
\hline Total & 270 & 100 \\
\hline \multicolumn{3}{|l|}{ Religion } \\
\hline Christianity & 253 & 93.7 \\
\hline Islam & 8 & 3.0 \\
\hline Free thinker & 9 & 3.3 \\
\hline Total & 270 & 100 \\
\hline
\end{tabular}

Table 1 portrays that out of the total of 270 respondents about $70 \%$ were below 31 years followed by those who were 31-35 years of age (20.4\%). Rural youth who were 36-40 years constituting $10.7 \%$ at the time of the survey were least represented. The age distribution of respondents indicate that majority of respondents were between 18 and 35 years, consistent with the definition of youth in Ghana (Ministry of Youth and Sports, 2010).

The sex distribution shows that 116 males constituting $43 \%$, and 154 females constituting 57\%, were involved in the study. More females therefore participated in the survey. This results probably from migration of young men to nearby towns to seek for means of survival.

Majority (45.2\%) of rural youth who participated in the survey had Junior High education equivalent of middle school in USA, followed by $32.6 \%$ who had primary education equivalent of elementary school in USA. Majority (77.8\%) of the respondents therefore had basic education (both primary and Junior High education) according to the educational 
system in Ghana. Few of the respondents, $8.1 \%$ did not attend formal school and $7.4 \%$ had Senior High education or high school respectively. Comparison of the percentage of respondents who had basic education $(77.8 \%)$ and those who proceeded to Senior High and Technical/Vocational education (14.1\%) shows the predominance of school drop-out among the young people. Some critical moments occurred in the life of rural youth accounting for the low level of secondary education among respondents. A participant for instance dropped out of school when the father died and had nobody to support him. In his own words he said:

I completed J.S.S 3. S.H.S schools wrote to me to study with them but I couldn't go due to financial difficulties. I completed in 1998. I did well too. My father died at that time. Nobody was willing to help me (Male, Kofi, 29)

According to Kofi even though he successfully completed Junior Secondary School (JSS) being the end of basic education in Ghana and was contacted by some Senior High Schools for admis sion he could not accept those offers. As noted, he faced financial strain after the death of his father. Financial challenge remained a key factor accounting for school drop-out of rural youth. According to Kwame a 27 year young man "When I completed I had admission at Opoku Ware School but I couldn't go due to financial problems" (Male, Kwame, 27)

Even though the participant was admitted to one of the prestigious high schools in Ghana, he could not further his education because of financial challenge. Poverty was identified as the cause of financial difficulties of the young people.

Out of the total of 270 rural young people, respondents who were married constituted the largest group (33.7\%) represented in the survey, followed by those who reported that they were co-habiting (30.7\%). The third category of respondents was those who said they had never married (24.1\%). Majority $(64.4 \%)$ of rural young people who participated in the study indicated either being married or co-habitating. Engagement of the rural youth in romantic relationship was therefore predominant resulting in high rate of child birth according to the respondents. This was acknowledged by a participant in focus group discussion (FGD) 3 when he said:

Here in particular a young lady can be between the ages 18 and 35. But because there is no job, a young lady at this age of 35 may have given birth to 5 or 6 children. Through this they become weak and can no longer be called youth. Some already look old women" (Male, Emmanuel, 33)

As noted by Emmanuel, a 33 year old male young man, a woman between ages of 18-35 who qualifies to be a youth may have 5 or 6 children. The frequency of child birth among youth is therefore evident in the community.

Christianity was reported by the highest number of participants (93.7\%) as their religion, followed by Islam (3.0\%). The least number of participants were reported for Free Thinkers (3.3\%). None of the participants reported engaging in traditional religion out of the data set. Significant percentage (96.7\%) of the respondents was therefore religious.

\subsection{Expectation of Nuclear Family Members'Support}

The study analysed whether or not rural youth expected nuclear family members' support to their employment trajectories. The expectation of father, mother, sibling and partner's support was therefore examined in relation to their past, present and future employment. Figure 1 presents results of expectation of nuclear family members' support to the employment paths of rural youth who participated in the survey.

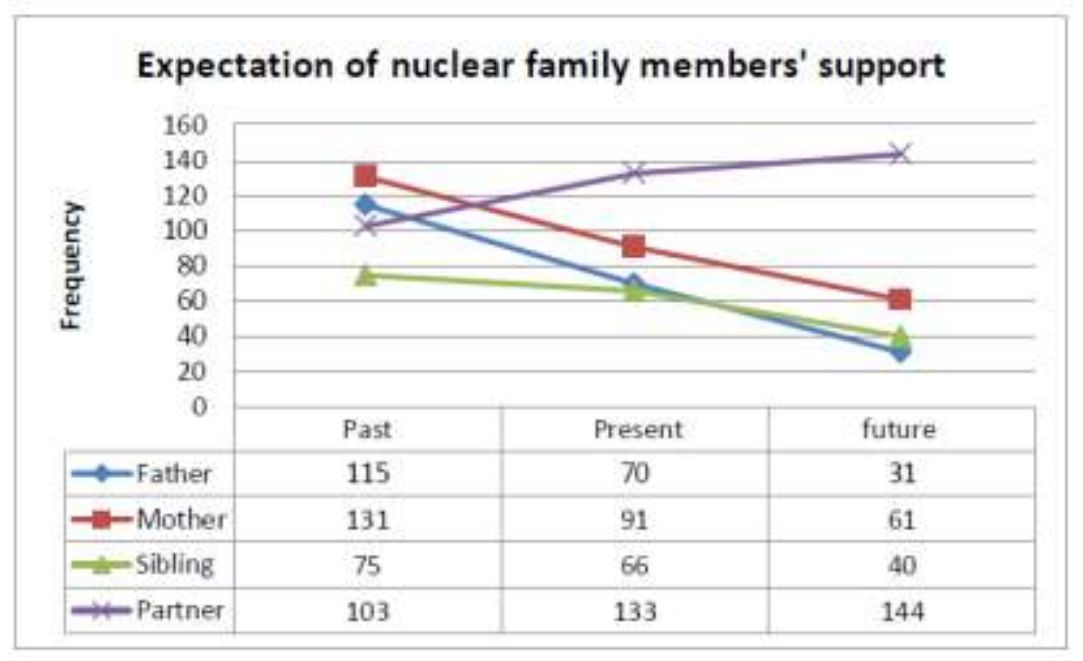

Figure 1. Expectation of nuclear family members' support 
Examining expectation of nuclear family members' support to rural youth past employment, Figure 1 indicates that though respondents reported that they expected employment support from their fathers (42.6\%) in relation to their past employment, their expectation of support declined with reference to their present employment (25.9\%) and future (11.5\%) employment aspirations. The decline in expectation of employment support was also evident in mothers' support from $48.5 \%$ to $33.7 \%$ and $22.6 \%$ in terms of past, present and future employment respectively. Though few rural youth expected support from their siblings, there was a reduction in expectation of siblings' support from $27.8 \%$ to $24.4 \%$ and $14.8 \%$ with reference to past, present and future employment respectively. Considering the present and future employment the data therefore shows that majority of young people did not expect support from their nuclear family members. However, expectation of support from partners was different. Out of the number of respondents who had partners, $38.1 \%$ expected support for their past employment. Also about half (49.3\%) of respondents who had partners expected support for their present employment and 53.3\% had such an expectation with reference to their future employment. There was therefore an increase in the expectation of partners' support from the past employment, to the present employment and future employment aspirations of the rural youth. Identifying the rationale for the high expectation of family members' support to employment paths of rural young people an interviewee invoked religious interpretation. Expressing his view he said that:

"The Bible even acknowledges that parents should take care of their children. If you take care of your children for their teeth to grow, they will also take care of you for your teeth to come out (Ghanaian proverb)" (Male, Dan, 29)

This interviewee drew inspiration from the Bible, Christians' holy book and a Ghanaian proverb, in explaining expectation of parents' support. Reciprocity was also evident in his statement. Parents' support to some extent results in children's support during parents' old age. However, as the findings indicate, expectations of nuclear family members' support were high in terms of their past employment, reduced over the present and declined further with reference to future employment plans. Majority of the rural youth therefore did not expect and receive employment support from their family networks.

The expectation of nuclear family's support is very characteristic of Ghanaian society. Acknowledging this situation, Langevang $(2008$, p. 2045) writes that this "ideal is strongly held on to today by young people who regard their parents or other older family members to be responsible for 'setting them up for life'. In return the young are expected to respect the authority of their parents or guardians, help them in day-to-day matters, help in the upbringing of smaller siblings, and accumulate enough resources to be able to take care of their parents when they are elderly". Expectation of family's support is manifested because of the collectivistic culture in Ghana. Apart from cultural explanation of the high level of expectation of family's support, reference was made to religious ideas. With majority $(96.7 \%)$ of the respondents reporting to be religious they acknowledged that God expects parents to support their children. Parents' support inadvertently results in children's support during parents' old age. Though this ideal reciprocal relationship between parents and children are acknowledged by the young people, Lange vang (2008) finds that in practice they are not being fulfilled. In fact, "lack of parental economic support was the most commonly stated reason for young people's failure to follow their desired futures" (Langevang, 2008, p. 2045).

\subsection{Expectation of Extended Family Members'Support}

The study analysed expectation of extended family members' support to the respondents'employment paths. Expectation of support from grandparent(s), uncle (s), aunt (s) and cousin (s) were examined. These social networks were deemed important from the focus group discussions. Table 2 presents results of the analysis. 
Table 2. Expectation of Extended Family's Support

\begin{tabular}{|c|c|c|c|}
\hline $\begin{array}{l}\text { Extended family } \\
\text { Support }\end{array}$ & $\begin{array}{l}\text { Past } \\
\text { Employment } \\
\text { N (\%) }\end{array}$ & \begin{tabular}{l}
\multicolumn{1}{c}{ Present } \\
Employment \\
N (\%)
\end{tabular} & $\begin{array}{l}\text { Future } \\
\text { Employment }\end{array}$ \\
\hline \multicolumn{4}{|l|}{ Grandparents } \\
\hline Yes & $23(8.5)$ & $9(3.3)$ & $10(3.7)$ \\
\hline No & $166(61.5)$ & $165(61.1)$ & $183(67.8)$ \\
\hline N/A & $81(30.0)$ & $96(35.6)$ & 77 (28.5) \\
\hline Total & $270(100)$ & $270(100)$ & $270(100)$ \\
\hline \multicolumn{4}{|l|}{ Uncles } \\
\hline$\overline{\text { Yes }}$ & $15(5.6)$ & $24(8.9)$ & $22(8.1)$ \\
\hline No & $202(74.8)$ & $178(65.9)$ & $199(73.7)$ \\
\hline N/A & 53 (19.6) & $68(25.2)$ & 49 (18.1) \\
\hline Total & $270(100)$ & $270(100)$ & $270(100)$ \\
\hline \multicolumn{4}{|l|}{ Aunts } \\
\hline Yes & $41(15.2)$ & $42(15.6)$ & 34 (12.6) \\
\hline No & $198(73.3)$ & $181(67.0)$ & $208(77.0)$ \\
\hline N/A & $31(11.5)$ & $47(17.4)$ & $28(10.4)$ \\
\hline Total & $270(100)$ & $270(100)$ & $270(100)$ \\
\hline \multicolumn{4}{|l|}{ Cousins } \\
\hline Yes & 39 (14.4) & $28(10.4)$ & $19(7.0)$ \\
\hline No & $196(72.6)$ & $210(77.8)$ & $226(83.7)$ \\
\hline N/A & $35(13.0)$ & 32 (11.9) & $25(9.3)$ \\
\hline Total & $270(100)$ & $270(100)$ & $270(100)$ \\
\hline
\end{tabular}

Table 2 shows that out of the 270 rural youth who participated in the survey o ver $60 \%$ of them did not expect employment support from their grandparents with reference to their past, present and future employment. Similarly, majority of the respondents, that is about three quarters (74.8\%) did not have any expectation of uncles support in terms of past employment, $65.9 \%$ and $73.7 \%$ had no expectation of support from uncles for their present and future employment respectively. This finding is inconsistent with the socio-cultural notion of matrilineal societies in Ghana such as the study area (Amankyea) where uncles are supposed to play a key role in young people's life. . Again, examining rural youth employment trajectories, the data revealed that majority of the respondents that is, $73.3 \%, 67 \%$ and $77 \%$ did not expect support from their aunts in terms of their past, present and future employment respectively. Similarly, majority of respondents, $72.6 \%, 77.8 \%$ and $83.7 \%$ did not expect support from their cousins in relation to their past, present and future employment activities.

\subsection{Nuclear Family Members as Supporters of Rural Youth Employment Paths}

Table 3 presents results on whether or not the nuclear family including father, mother, siblings and partners provide support to rural youth's employment activities.

Table 3. Nuclear family as supporters of Rural Youth Employment Path

\begin{tabular}{lll}
\hline $\begin{array}{l}\text { Nuclear family } \\
\text { Support }\end{array}$ & $\begin{array}{l}\text { Past } \\
\text { Employment } \\
\mathbf{N}(\%)\end{array}$ & $\begin{array}{c}\text { Present } \\
\text { Employment } \\
\mathbf{N}(\boldsymbol{\%})\end{array}$ \\
\hline $\begin{array}{l}\text { Father } \\
\text { Disagree }\end{array}$ & $171(63.3)$ & $179(66.3)$ \\
Neutral & $9(3.3)$ & $8(3.0)$ \\
Agree & $54(20.0)$ & $41(15.2)$ \\
N/A & $36(13.3)$ & $42(15.6)$ \\
Total & $270(100)$ & $270(100)$ \\
Mother & & $160(59.3)$ \\
Disagree & $151(55.9)$ & $75(27.8)$ \\
Agree & $90(33.3)$ & $35(13.0)$ \\
N/A & $29(10.7)$ & $270(100)$ \\
Total & $270(100)$ & $196(72.6)$ \\
Siblings & & $38(14.1)$ \\
Disagree & $200(74.1)$ & $36(13.3)$ \\
Agree & $36(13.3)$ & $270(100)$ \\
N/A & $34(12.6)$ & $36(13.3)$ \\
Total & $270(100)$ & $138(51.1)$ \\
Partner & & $96(35.6)$ \\
Disagree & $39(14.4)$ & $270(100)$ \\
Agree & $102(37.8)$ & \\
N/A & $129(47.8)$ & $270(100)$ \\
Total & & \\
\hline
\end{tabular}


Analysing data on family members as supporters of rural youth past employment, Table 3 shows that in terms of past employment $63.3 \%$ of respondents disagreed that fathers supported them, $55.9 \%$ disagreed that their mothers supported them and $74.1 \%$ also disagreed that they were supported by their siblings. Majority of the rural youth who participated in the survey therefore reported not receiving support from their fathers, mothers and siblings. The percentage of respondents who received employment support from partners for their past employment however was quite significant (37.8\%). The low family networks' support to rural youth past employment, was also evident when analysing their present employment. Majority of the respondents represented by $66.3 \%, 59.3 \%$ and $72.6 \%$ did not receive support from their fathers, mothers and siblings respectively in terms of their present employment. Few of the respondents (13.3\%) however reported that they did not receive support from their partners. The data therefore reveals that majority of respondents reported not receiving support from their parents. Exploring family's support to young people's employment further, some participants argued that it was uncommon in the rural area for parents to help. Dorcas, a female participant in FDG 2 had this to say:

\section{Here only few individuals receive support from their parents. It rarely happens (Female, Dorcas, 24).}

The study revealed that majority of respondents reported not receiving support from their parents and siblings (Table 3). In deed some interviewees even said it was rare for parents to offer support. So although Wong \& Liu (2009:83) argue that "parents play a very important role in all aspects of a young person's life, including those critical decision-making points such as choosing a career", the views of the rural youth on employment support were different. Comparing the receipt of support from fathers and mothers, respondents who reported that they received employment support from their mothers $(33.3 \%, 27.8 \%)$ were more than those who received support from their fathers $(20 \%, 15.2 \%)$ in terms of their past and present employment. This finding supports the views of the influential role of mothers identified by Bojuwoye \& Mbanjwa (2006), Muthukrishna \& Sokoya (2008), and Shumba \& Naong (2012) in career and employment decisions of young people.

Female youth who participated in the survey stated that they received support from their partners, more than male young people. The responsibility to support partners was therefore more on male young people. A possible reason as noted by Lange vang (2008) is that being able to take good care of a girlfriend bestows one with status, as it is a sign of wealth and masculinity. Indeed there is the probability of losing a lady if a man is unable to prove his ability to provide her needs (Langevang, 2008). The responsibility to support partners is therefore more on male young peo ple.

\subsection{Extended Family Members as Supporters of Rural Youth Employment Paths}

Table 4 presents the results of data on extended family members as supporters of past and present employment of rural youth.

Table 4. Extended family members as supporters of Rural Youth Employment Path

\begin{tabular}{|c|c|c|}
\hline $\begin{array}{l}\text { Extended family } \\
\text { Support }\end{array}$ & $\begin{array}{l}\text { Past } \\
\text { Employment } \\
\text { N }(\%)\end{array}$ & \begin{tabular}{l}
\multicolumn{1}{c}{ Present } \\
Employment \\
N $(\%)$
\end{tabular} \\
\hline \multicolumn{3}{|l|}{ Grandparent } \\
\hline$\overline{\text { Disagree }}$ & 167 (61.9) & $165(61.1)$ \\
\hline Agree & $22(8.1)$ & $9(3.3)$ \\
\hline N/A & $81(30.0)$ & $96(35.6)$ \\
\hline Total & $270(100)$ & $270(100)$ \\
\hline \multicolumn{3}{|l|}{ Uncle } \\
\hline Disagree & $189(70.0)$ & $183(67.8)$ \\
\hline Agree & $28(10.4)$ & $19(7.0)$ \\
\hline N/A & $53(19.6)$ & $68(25.2)$ \\
\hline Total & $270(100)$ & $270(100)$ \\
\hline \multicolumn{3}{|l|}{ Aunt } \\
\hline Disagree & $200(74.1)$ & $197(73.0)$ \\
\hline Agree & 39 (14.4) & $26(9.6)$ \\
\hline N/A & $31(11.5)$ & $47(17.4)$ \\
\hline Total & $270(100)$ & $270(100)$ \\
\hline Cousin & $216(80.0)$ & $223(82.6)$ \\
\hline Disagree & $19(7.0)$ & $15(5.6)$ \\
\hline Agree & $35(13.0)$ & $32(11.9)$ \\
\hline N/A & $270(100)$ & $270(100)$ \\
\hline Total & & \\
\hline
\end{tabular}


they did not receive employment support from uncles, aunts and cousins for their past employment were $70 \%, 74.1 \%$ and $80 \%$ respectively. Majority of rural youth who participated in the study again did not receive support from extended family members when data on their present employment was analysed. About $61 \%, 68 \%, 73 \%$ and $83 \%$ did not obtain support from their grandparents, uncles, aunts and cousins respectively with reference to their present employment.

Divergent views were evident on family members' support to rural youth employment during the focus group discussions. Indeed, majority of participants however argued vehemently on family members' lack of support. For them, evidence in support of assistance from family members was scarce. Rather, extended family members preferred to support other social events such as organizing funerals instead of supporting the socio-economic advancement of rural youth. Daniel a 25 year old young man for example expressed this opinion when he said that:

"Why I am saying they don't help is that, when a person goes into difficulty they won't mind you but let somebody die in the house or you die yourself, you will see the expenditure that will be incurred on the building alone, awaiting the funeral celebration. That even shows that the family doesn 't have any help for you. The help they'll offer is organizing funeral celebration for profit, when you die. Pushing somebody forward is not a lot here" (Male, Daniel, 25)).

According to this participant majority of the families did not support the young people. For him emphasis was placed on celebrating the dead rather than improvement in the welfare of the living. The study therefore found extended family members as unsupportive to the employment paths of rural young people (Table 4). This finding contrasts the views that stress on the important role of extended family members on career choices and aspirations emphasized by Whiston \& Keller (2004). Again the finding is contrary to the widely held traditional notion of support offered by the extended family to its members in Ghana. The study therefore found a decline in the support offered by the extended family members, contrary to the views of Aryeetey et al (2013) that its traditional relevance has not waned especially in rural areas. Traditionally, support by uncles in matrilineal societies in Ghana is highly recognised. This traditional vie w of family was reiterated by Aryeetey et al (2013) that in Ghana aunts and uncles have significant influence on rural young people's employment choices and aspirations. However the study revealed the widespread view that the young people did not receive support from their uncles. This finding therefore questions the expectation and dependence on uncles' support in matrilineal societies in Ghana in contemporary times. Though some participants in the interviews and focus group discussions attributed the unsupportiveness of extended family members to widespread poverty, others did not wholly agree. For them it was a matter of prioritization, since family members support the organization of social events such as funerals, but fail to provide employment support to the young people. Despite the rural youth's report of unsupportiveness by the family, it appears they received some support in the form of land, farming skills, information about job opportunities among others. The support they received however was not deemed by them as significant, resulting in majority indicating they did not receive support

\section{Conclusion and Recommendation}

The study found that majority of rural youth did not expect and receive employment support from their nuclear (fathers, mothers, siblings) and extended (grandparents, uncles, aunts, cousins) families. Even though the social capital theory argues that members in social relations expect and receive benefits from their social networks due to the idea of reciprocity, the rural youth indicated they had no such expectation especially in terms of their present and future employment plans. This might probably be due to the unfulfilled expectation of support from their social networks in the past. The study recommends the need to encourage family networks through workshops and seminars to prioritize employment support to rural young people to reduce reliance on government of Ghana.

The study is limited in terms of its geographic scope. It focused on youth in a rural community in Ghana which limits the ability to generalize findings widely to other communities. Further studies can therefore include youth in other rural communities to enhance generalization. Future studies can also undertake a more rigorous statistical analysis to unravel correlation and causalities of factors that influence family networks' employment support to rural young people. Other studies can also explore family members' perceptions of "help" in the context of employment, to the rural youth.

\section{Acknowledgement}

The researchers acknowledge the funding support received from DANIDA under the Building Stronger Universities (BSU-1) project. We wish to appreciate the logistical and supervisory support from Kwame Nkrumah University of Science and Technology, Kumasi, Ghana, DANIDA Fellowship Centre and Copenhagen Business School, Copenhagen, Denmark.

\section{References}

Acquaah, M. (2006). The impact of managerial networking relationships on organizational performance in Subsaharan Africa: Evidence from Ghana. Organization Management Journal,3(2), 115-138. https://doi.org/10.1057/omj.2006.13 
Acquaah, M. (2011) Business strategy and competitive advantage in family businesses in Ghana: The role of social networking relationships. Journal of Developmental Entrepreneurship, 16(1), 103-126. https://doi.org/10.1142/S1084946711001744

African Economic Outlook. (2012). Special theme: Promoting youth employment. Available: http://www.africaneconomicoutlook.org/en/in-depth/youth_employment/

Alderfer, C. (2004). Afamily therapist's reaction to the influences of the family of origin on career development: Areview and analysis. The Counseling Psychologist, 32(4), 569-577. https://doi.org/10.1177/0011000004265963

Alika, H. I. (2012). Career choice in engineering: The influence of peers and parents implication for counselling. College Student Journal, 46(3), 537-542.

Amankrah, J. Y. (2012). Youth unemployment in Ghana: Prospects and challenges Downloaded from: www.cepa.org.gh/research/researchpapers/Youth73.pdf. Accessed on 2nd October, 2017.

Anyidoho, N. A., Leavy, J., \& Asenso-Okyere, K. (2012). Perceptions and aspirations: Acase study of young people in Ghana's cocoa sector. IDS Bulletin, 43(6), 20-32.https://doi.org/10.1111/j.1759-5436.2012.00376.x

Aryeetey, E. B. D., Doh, D., \& Andoh, P. (2013). Choosing an apprenticeship: skills preferences amongst the youth. International Development Planning Review, 35(2), 135-153. https://doi.org/10.3828/idpr.2013.10

Assimeng, J. M. (2006). Understanding society: an introduction to sociology for African students. Accra. Woeli Publishing Services.

Baffour-Awuah, D. (2013) Ghana country report for the 2014 Ministerial conference on youth employment. Tema. Workforce Development Institute

Barker, J. D. (2012). Social capital, homeless young people and the family. Journal of youth studies, 15(6), 730-743. https://doi.org/10.1080/13676261.2012.677812

Bojuwoye, O., \& Mbanjwa, S. (2006). Factors impacting on career choices of Technikon students from previously disadvantaged high schools. Journal of Psychology in Africa, 16(1), 3-16.

Bourdieu, P. (1985). The social space and the genesis of groups. Theory and society, 12 (6), 723-744.

Bourdieu, P. (1993). Sociology in question. London. Sage.

Byun, S. Y., Meece, J. L., Irvin, M. J., \& Hutchins, B. C. (2012). The role of social capital in educational aspirations of rural youth. Rural sociology, 77(3), 355-379. https://doi.org/10.1111/j.1549-0831.2012.00086.x

Ferry, N. M. (2006). Factors influencing career choices of adolescents and young adults in rural Pennsylvania. Journal of Extension, 44(3), 1-6.

Gargiulo, M., \& Benassi, M. (2000). Trapped in your own net? Network cohesion, structural holes, and the adaptation of social capital. Organization science, 11(2), 183-196. https://doi.org/10.1287/orsc.11.2.183.12514

Ghana Statistical Service. (2012) Provisional population figure (Census 2010). Available at http://www.statsghana.gov.gh/_Accessed on 2nd October, 2017

Giddens, A., \& Sutton, P. W. (2013). Sociology. 7th edition. Cambridge: Polity Press.

Gough, K. V., Lange vang, T., \& Owusu, G. (2013). Youth employment in a globalising world. International Development Planning Review, 35(2), 91-102. https://doi.org/10.3828/idpr.2013.7

Howard, K. A., Carlstrom, A. H., Katz, A. D., Chew, A. Y., Ray, G. C., Laine, L., \& Caulum, D. (2011). Career aspirations of youth: Untangling race/ethnicity, SES, and gender. Journal of Vocational Behavior, 79(1), 98-109. https://doi.org/10.1016/j.jvb.2010.12.002

Independent Evaluation Group. (2012). World Bank and IFC Support for Youth Employment Programs. Washington, D.C.: World Bank.

Israel, G. D. (2009). Determining Sample Size. University of Florida IFAS Extension. http://edis.ifas.ufl.edu/pd006 Accessed on 4th January, 2014.

Kniveton, B. H. (2004). The influences and motivations on which students base their choice of career. Research in Education, 72(1), 47-59. https://doi.org/10.7227/RIE.72.4

Kristensen, S., \& Birch-Thomsen, T. (2013). Should I stay or should I go? Youth and rural employment in Uganda and Zambia. International Development Planning Review, 34, 175-201. https://doi.org/10.3828/idpr.2013.12

Lange vang, T. (2007). Movements in time and space: using multiple methods in research with young people in Accra, 
Ghana. Children's geographies, 5(3), 267-282. https://doi.org/10.1080/14733280701445853

Lange vang, T. (2008). Claiming place: The production of young men's street meeting places in Accra, Ghana. Geografiska Annaler: Series B, Human Geography, 90(3), 227-242. https://doi.org/10.1111/j.1468-0467.2008.289.x

Leavy, J., \& Smith, S. (2010). Future farmers: Youth aspirations, expectations and life choices. Future Agricultures Discussion Paper, 13, 1-15.

Mau, W. C., \& Bikos, L. H. (2000). Educational and vocational aspirations of minority and female students: A longitudinal study. Journal of Counseling \& Development, 78(2), 186-194. https://doi.org/10.1002/j.1556-6676.2000.tb02577.x

Mbiti, J. S. (1969). African religions \& philosophy. London: Heinemann.

Ministry of Employment and Labour Relations (2014) Government of Ghana National Employment Policy, Volume 1: Ghana: Ministry of Employment and Labour Relations

Ministry of Youth and Sports (2010). The National Youth Policy, Accra, Ghana: Ministry of Youth and Sports

Mudhovozi, P., \& Chireshe, C. (2012). Socio-demographic factors influencing career decision-making among undergraduate psychology students in South Africa. Journal of Social Sciences, 31(2), 167-176. https://doi.org/10.1080/09718923.2012.11893025

Muthukrishna, N., \& Sokoya, G. O. (2008). Gender differences in pretends play amongst school children in Durban, Kwazulu-Natal, South Africa. Gender and Behaviour, 6(1), 1577-1590. https://doi.org/10.4314/gab.v6i1.23405

Ngesi, M. J (2003). A study of systematic processes influencing educational change in a sample of Isi-Zulu Medium Schools. PhD Thesis, Unpublished. University of Natal, Pietermaritzburg, South Africa.

Okali, C., \& Sumberg, J. (2012). Quick money and power: Tomatoes and livelihood building in rural Brong Ahafo, Ghana. IDS Bulletin, 43(6), 44-57. https://doi.org/10.1111/j.1759-5436.2012.00378.x

Patton, M. Q. (2002). Qualitative research and evaluation methods. 3rd ed. London. Sage.

Salami, S. O. (2006). Influence of culture, family and individual differences on choice of gender-dominated occupations among female students in tertiary institutions. Gender and behaviour, 4(2), 814-833.

Shumba, A., \& Naong, M. (2012). Factors influencing students'career choice and aspirations in South Africa. J. Soc. Sci, 33(2), 169-178. https://doi.org/10.1080/09718923.2012.11893096

Vähäkangas A. (2004). The Crisis of Christian Marriage in Kyomo, A and Selvam, G. (eds), Marriage and Family in African Christianity, Nairobi: Acton Publishers.

Warah, R. (2008). Missionaries, mercenaries andmisfits: an anthology. Central Milton Keyes. Author House.

Waruta, D. W. (2005). Marriage and family in contemporary African society: challenges in pastoral counseling In Waruta, D.W. and Kinoti, H, W. (Eds.), Pastoral care in African Christianity Nairobi: Acton Publishers

Whiston, S. C., \& Keller, B. K. (2004). Expanding research concerning family influences on career development: Cultivating a number of brown spots. Counseling Psychologist, 32(4), 612-617. https://doi.org/10.1177/0011000004266009

Whiston, S. C., \& Keller, B. K. (2004). The influences of the family of origin on career development a review and analysis. The Counseling Psychologist, 32(4), 493-568. https://doi.org/10.1177/0011000004265660

White, B. (2012). Agriculture and the generation problem: rural youth, employment and the future of farming. IDS Bulletin, 43(6), 9-19. https://doi.org/10.1111/j.1759-5436.2012.00375.x

Winter, I. (2000). Towards a theorised understanding of family life and social capital. Melbourne: Australian Institute of Family Studies.

Wong S. C., \& Liu G. J. (2009) Will parental influences affect career choice? Evidence from hospitality and tourism management students in China. International Journal of Contemporary Hospitality Management, 22(1), 82-102. https://doi.org/10.1108/09596111011013499

Wu, Y. L. (2012). Examining the occupational aspirations of Taiwanese Aboriginal adolescents based on the developmental-contextual model of career development. Asia Pacific Education Review, 13(4), 757-769. https://doi.org/10.1007/s12564-012-9234-9

Yeboah, E. H. (2010). Microfinance in rural Ghana: A view from below (Doctoral dissertation). Birmingham. Uni versity of Birmingham. 
Yin, R. K. (2009). Case study research: Design and methods. London. Sage.

\section{Copyrights}

Copyright for this article is retained by the author(s), with first publication rights granted to the journal.

This is an open-access article distributed under the terms and conditions of the Creative Commons Attribution license which permits unrestricted use, distribution, and reproduction in any medium, provided the original work is properly cited. 